\title{
My Journey with Donald A.B Lindberg M.D.
}

\author{
Steven J. PHILLIPS M.D. ${ }^{1}$ \\ Cardiac Surgeon Emeritus, Iowa Heart Center \\ Associate Director, U.S. National Library of Medicine (retired)
}

Keywords. Donald A.B. Lindberg M.D., Potomac River, Cosmos Club, University of Missouri-Columbia, U.S. National Library of Medicine

\section{Introduction}

Donald A. B. Lindberg M.D. was my friend, my colleague, someone I looked up to, but most importantly, a man with whom I could comfortably share confidences.

We spent quality time together at the National Library of Medicine (NLM), at meetings, dinners, at the Woods Hole Conference, and during national and international travels. We enjoyed many evenings, relaxing in a restaurant, and especially at Don and Mary Lindberg's home.

We relived memories of growing up in Brooklyn. We chuckled over the fierce competition between "D'EM BUMS" fans (the Brooklyn Dodgers), and the pin-striped, pompous, New York Yankees. The N.Y. Giants? They were simply the 'other team.' We reminisced about Coney Island, the wonderful museums, parks, riding the subway, and biking to ride the Staten Island Ferry. We remained awed by the Empire State Building, Central and Prospect Parks with their zoos, Broadway shows, Radio City Music Hall, and on and on and on.

We rarely repeated ourselves as the experiences were nearly unlimited. I admit these memories became more vivid, expansive, and colorful when our discussions were augmented by a few of Don's bourbons with branch water.

Although we never solved the world's problems, we were not shy to address them. Thankfully, Mary Lindberg monitored my evening sessions with Don. She fed us delicious dinners, and on occasion, guided Don to bed and me to a spare bedroom.

The memoir's next sections address a few topics that touch on our friendship. The topics include: how and when I met Don; how his work impacted my career as a cardiovascular surgeon two decades before we met; impromptu days off with Don on a boat in the Potomac river; his ongoing professional support; and a closing tribute.

\section{How We Really Met and Quick Responses}

In 1993, I was practicing cardiac surgery in Des Moines, Iowa, geographically located in the north central U.S. My office messaged me that: 'Dr. Donald Lindberg, the Director of the National Library of Medicine' was trying to reach me. The name 'Don Lindberg'

\footnotetext{
${ }^{1}$ Corresponding author: sp226@icloud.com
} 
rang a bell, but I could not recall why. The long hiatus between our first meeting and my initial exposure to Don is discussed in the next section.

Intrigued, I returned Don's call. To my surprise and delight, he invited me to serve on NLM's Board of Regents (BOR). The BOR met three times a year at NLM in what is now called the Lindberg Board Room.

Each meeting was, in my mind, at the level of a postdoctoral seminar in biomedical informatics. A BOR membership lasts four years, and I was the chair when I rotated off in 1998. To my delight, Don asked me to continue as a 'Consultant to the Board.' I was captivated with NLM's innovative projects and programs and its world-class staff, and I felt honored to remain connected.

A year later, when Harold L. Schoolman M.D. (NLM's Deputy Director for Research and Education) retired, Don invited me to fill the position. Don's invitation was on a Wednesday afternoon - just after a BOR meeting adjourned. I accepted on the spot.

Don asked when I could start and was startled when I replied: 'probably Monday.' At the time, Don was unaware my daughter just completed a master's program at American University and was flying off to begin a doctorate program at the University of Washington-Seattle. She left an empty, unsold, move-in immediately apartment, about a mile from the NIH campus.

So, I started on Monday.

\section{How We Almost met - or Like Two Ships Passing in the Night}

Don's innovative thinking and achievements impacted me about two decades before my invitation to join NLM's Board of Regents. Yet, my initial exposure to Don's work was linked to a career job change.

In 1974, I was recruited from the University of Oregon by the staff and administration of Mercy Hospital in Des Moines to establish a cardiac surgery program. At the time, the Mercy Hospital and Clinics serviced a population of approximately 700,000 people. The nearest heart surgery program was about 100 miles away. Des Moines patients and their families were forced to travel regionally (south to the University of Iowa or north to the Minnesota-based Mayo Clinic) for cardiac surgery.

In short, my new job was a response to a need for better, local access to cardiac care coupled with Iowa's harsh winters, which often jeopardized regional travel for patients and families.

To prepare for my arrival, the hospital flew my future Des Moines clinical team to train with me in Oregon. The goal was to teach my Des Moines team to collaborate similar to the heart surgery group I was leaving at the University of Oregon. The remote training activity was designed to enable us 'to hit the ground running,' which was critical. Before I arrived at Mercy, I had a waiting list of 84 patients.

Yet in team building, I did not set up a modern pathology laboratory to support our new surgical group. As busy as I was on day one, it was apparent that Mercy Hospital's cardiac team would not thrive if we failed to prepare the hospital's pathology laboratory optimally to assist a suddenly very active surgical unit.

I quickly learned that the University of Missouri had a world-class laboratory and pathology program that supported the university's clinical center. I cannot describe our Des Moines laboratories deficiencies better than to suggest our technology was 
equivalent to a vacuum tube TV with rabbit ears, while Missouri's pathology technology was $5 \mathrm{~K}$.

In turn, arrangements were made for our in-house pathologists and technicians to visit the University of Missouri's Hospital and Clinics (in Columbia, Missouri) to learn how to upgrade Mercy's laboratory practices. What I did not know then (and discovered later) was Mizzou's lab was under the direction of Donald A. B. Lindberg M.D., a Professor of Pathology and Director of the Information Science Group - University of Missouri-Columbia.

While we did not meet until almost two decades later, I became aware of Don's work and skill because he provided a template and the training to modernize Mercy Hospital's pathology laboratory, which boosted my cardiac surgery program.

\section{Adventure on the Potomac}

Despite years of clinical influence and institutional collaboration, it was not always work with Don.

For example, we took an impromptu trip once during a typical, sweltering, middle August in Washington D.C. when I was director of NLM's Special Information Services Division (SIS) division - my second administrative position at NLM.

The voyage began on a Tuesday morning, when I routinely met with Don in his office on the NIH campus. Since it was a short drive from my Democracy Blvd. office to Don's office in building 38, there was insufficient time for the car's air conditioning to kick in. In addition, just the walk from the parking garage to the mezzanine area (where his office was located) left me in a pool of sweat. As I slumped into Don's office, he took one look at me and said, 'boy, it's hot and humid.'

At the start of the meeting, Don mentioned Mary was out of town for the week. I said so was my wife, Susan. Grinning mischievously at each other, we instantly came up with the idea of playing hooky. After a brief pause, Don said 'BOAT.'

I responded: 'Don... you bring the food and libations, and I will be responsible for the gasoline.'

In moments, a plan was hatched! We informed our respective staff that we were unavailable for the next few days (Wednesday through Friday). We designated our responsibilities to our deputies and disappeared.

We met at a Marina at about 10:00 am the following morning. We gassed-up stored our provisions and set sail. The temperature was already inching toward the mid-90s, with no breeze with the humidity at least $300 \%$.

I started to organize the galley but found the cabin stifling hot. To avoid heatstroke, I asked Don to turn on the air conditioning. Don unsuccessfully fooled with some switches and knobs, then informed me he was unsure how to turn it on: 'that Mary usually did it.' After 30 minutes of flipping switches, Don gave up, so I began looking for the rescue markers and flare gun. It was evident that we were going to rough it for a while.

Did I mention the boat's engine would not start? It finally fired up when we discovered that we had to prime the gas feed.

Off we went, cruising down the Potomac, toasting our escape with a cocktail. We were relaxed with not a care in the world until a couple hundred thousand hungry mosquitoes attacked us. Don, an experienced and seasoned sailor, responded immediately. He hit the gas and left the swarm behind us. 
We both agreed that the best response to the attack was another bourbon.

The afternoon passed, the breeze picked up, and some ominous rain clouds appeared. When we reached an area opposite the Quantico Marine base, we were greeted by a welcome cool drizzle. I took a quick refreshing dip into the Potomac then dutifully rejoined Don to help finish the first bottle of bourbon. When the rain began to squall, we ducked into the cabin and closed the door and hatches to prevent the many gallons of rainwater from flooding the cabin.

Again, without success, we tried to turn on the air conditioning. In turn, the only answer to the latter predicament was to mix martinis.

The rain stopped, so we opened the cabin to the outside. Cool air flooded in comfortably around us.

We chatted, enjoyed a cold supper, and yawned. Don mumbled something about getting into bed, and I chose to sleep on deck. We awoke just after sun rise. I gathered up some breakfast while Don busied himself with coffee.

We spent a good part of the day fishing, but the fish were luckier and smarter. We discussed everything from Kipling to politics and the opera. We again reminisced about growing up in New York City, the Statue of Liberty, ethnic restaurants, and other common experiences. After much discussion, we agreed that the N.Y. Museum of Natural History was one of our favorites.

Throughout the day, we shared stories about our adventures in life, college, medical school, and how much we missed the multicultural and multiethnic environment of New York. We agreed that living in Missouri and Iowa also was amazing and how neither of us regretted the range of our experiences. I described to Don the beginnings of my cardiac program and the contributions of his pathology lab.

He smiled.

By Friday afternoon, we ran out of food and drinks. We looked at each other and agreed this great adventure was over, and it was time to go home. We honestly had fun, although we both required a weekend of rest to recover.

\section{Don Had My Back}

Don's enduring support is illustrated by explaining when he substituted for me and requested that I return to NLM following a prior exodus.

To backup, NLM initiated a program to educate high school students on careers in the medical sciences during my term as NLM's Deputy Director for Research and Education. The conference was named after Michael DeBakey M.D., the distinguished heart surgeon and medical educator and a long-time member of NLM's Board of Regents.

Indeed, the first students in the program were from the Michael E. DeBakey High School for Health Professions in Houston, TX., where Dr. DeBakey then lived.

Subsequently, NLM sponsored DeBakey conferences in other cities that were piggybacked onto a scheduled conference of medical professionals. The simultaneous scheduling was so we could ask prominent scientists attending the conference to meet with students. No requested speaker ever refused.

One of the venues selected for the DeBakey conference was in Chicago during the 2004 annual meeting of American Society for Artificial Internal Organs (ASAIO), an organization I was professionally affiliated with. After I left NLM and the Deputy 
Director for Research and Education position in 2002, I continued to manage the DeBakey conferences (with NLM's support).

All the arrangements for the DeBakey conference were in place. The students were selected, parental permission slips signed, transport to the conference arranged, and the speakers primed and ready. As usual, I was both a facilitator and moderator.

However, I had a medical emergency the day before my Chicago departure, which required immediate surgery. Since I was in Iowa instead of Bethesda, no one at NLM was aware of my unexpected incapacitation. My wife Susan called Don and explained my impending absence.

Don immediately came to the rescue. He dropped everything, canceled all plans, and flew to Chicago to host the DeBakey conference, AND he called Susan daily to check on my progress.

The second example of Don's support was his invitation to me to return to NLM in 2006. The offer was significant because I left NLM in 2002 in a departure that I soon determined a mistake. Don was not happy with my 2002 exit, and we rarely communicated for a short period.

Nevertheless, in 2006 I was asked by the National Heart Lung and Blood Institute within the National Institutes of Health to consider leading a new Division. I called Don for advice, and he said something to the effect of: 'to hell with that... come back to NLM.' I was delighted, and I returned as the director of NLM's Specialized Information Services division.

From my perspective, Don's actions in both circumstances say everything about him.

\section{Epilogue, My Two Cents}

Broadly speaking, if I had to describe Don with one word - it would be ARTIST. Don expressed his artistic bent through many creations and accomplishments, and often beautifully with a camera.

Artistry enables a person to see the beauty, the good, the potential, and the benefit in people, things, and processes. Some examples include Don's ongoing support for students, minorities, and individuals trying to better themselves. Don promoted, enhanced, and actively supported a diverse and abundant array of imaginative programs and projects at NLM.

However, an artist also perceives the 'ugly.' Don spent his career addressing 'ugly' examples that adversely impacted medical practice and the public. These included: dysfunctional health information technologies; occasionally parochial actions by medical stakeholders; unstructured clinical data; the enduring challenges that limited user access to printed medical journals and books; the monetization of the Internet; and disconnected medical libraries, among others.

With a multidimensional perspective, Don succeeded and improved access to health information at every level.

Beyond NLM, Don contributed intellectually to many organizations, including his favorite, the Cosmos Club in Washington, D.C. He encouraged others to do so.

Don's achievements were visionary, engendered by a caring intelligence, to promote public education and support physicians, nurses, pharmacists, and other healthcare workers. He wanted NLM's resources to enable provider self-improvement and enhance 
patient care. He also envisioned NLM's resources as helping patients and their families understand medical information and the health care delivery system.

THANK YOU, DON! 